\title{
Identifying Key Epistemological Challenges Evaluating in Indigenous Contexts: Achieving Bimaadiziwin through Youth Futures
}

\section{Robert P. Shepherd and Katherine A. H. Graham \\ Carleton University}

\begin{abstract}
The evaluation field's understanding of Indigenous ontologies and epistemologies must improve in ways that do not serve to privilege Western ways of knowing or governmental priorities for accountability. The literature has not identified ways to bridge these in practical ways, or to move the field to balance community and government needs. This article describes some prevailing epistemological and methodological issues related to evaluation and then identifies practical challenges bridging Western and Indigenous approaches, using the example of the Indigenous Youth Futures Partnership project (IYFP), a seven-year SSHRC-sponsored grant. It is suggested that there are approaches that work well in these contexts but that agency is vitally important to establish reciprocity.
\end{abstract}

Keywords: community-based evaluation, Indigenous epistemology, Indigenous evaluation, Indigenous youth, transformative evaluation

Résumé : La compréhension des ontologies et épistémologies autochtones dans le domaine de lévaluation doit s’améliorer de manière à ne pas privilégier les modes de connaissance occidentaux et les priorités gouvernementales en matière de responsabilisation. La recherche nia pas trouvé de moyens pratiques de combler ces lacunes ni de trouver des moyens déquilibrer les besoins de la collectivité et ceux du gouvernement. L'article décrit l'ontologie et l'épistémologie autochtones liées à lévaluation, puis cerne les défis pratiques qui font le pont entre les approches occidentales et autochtones à l'aide de l'exemple du projet Partenariat pour l'avenir des jeunes autochtones (PAJA), qui profite d'une subvention de sept ans du CRSH. On suggère qu'il existe des approches qui fonctionnent bien dans ces contextes, mais que l'autonomie est d'une importance vitale pour établir la réciprocité.

Mots clé : évaluation fondée sur la communauté, épistémologie autochtone, évaluation autochtone, jeunesse autochtone, évaluation transformatrice

Although there has been an increased demand for effective evaluation practice in Indigenous contexts (Cram, Chilisa, \& Mertens, 2016; Cram \& Mertens, 2015), the imposition of Western post-positivist approaches has been predominant in

Corresponding Author: Robert Patrick Shepherd, School of Public Policy \& Administration, 1125 Colonel By Dr., Rm. 5126RB, Ottawa, ON, K1S 5B6; RobertP.Shepherd@carleton.ca 
governmental evaluations, with the result that the value of evaluation for policymaking conducted in these contexts is limited at best (Bowman, 2017; Chilisa, 2012; Mertens, 2018). Kovach (2009) argues that Indigenous research, including by extension Indigenous evaluation, is premised on Indigenous ways of knowing that are not homogenous but rather based in tribal cultures. She explains that Indigenous identities must be acknowledged in the research effort out of respect. Although Indigenous epistemologies vary by context and conditions, Kovach suggests that there are commonly held, enduring beliefs that provide a picture of a holistic worldview that values relations over science and values cultural protocols and norms. Such worldviews are distinct from other worldviews, even for other cultural minority groups.

This article focuses on the need for, and the associated challenges of, bridging Indigenous and Western evaluation methods in Indigenous contexts. We provide a theoretical exploration of these differences and illustrate some of the issues through a discussion of the work of the Indigenous Youth Futures Partnership (IYFP), which is a community-based research project that aims to understand how to create sustainable conditions for First Nations youth to flourish and become leaders in their own communities. We are both co-investigators in this project. We are academics of settler background with collectively over 60 years of experience in community-based research with Indigenous peoples, including research intended to inform public policy. The authors have worked with communities in trauma in the past, and with the necessity of connecting or bridging community experiences with public policymaking so that better approaches can be designed and considered for implementation. We understand that policymaking with respect to Indigenous communities often lacks the benefit of context, and we recognize difference as important.

The first section of the article describes key challenges when evaluating in Indigenous contexts that extend from epistemological and ontological difference, as described in the introduction to this volume. We use the literature to provide a generalized understanding of the key differences and indicate where Western postpositivist scientific approaches may not always be compatible or even desirable in the practice of evaluation in Indigenous contexts. We then provide a description of the Indigenous Youth Futures Partnership project and a glimpse into some of the challenges and lessons we have learned carrying out evaluation practice in Indigenous contexts through our experience at the mid-point of our seven-year project. In particular, we explore how the social sciences understand power relations and how co-production approaches have an influence. We highlight the way in which instrumental concepts such as building trust, generating strength-based community capabilities, and working with patience and different conceptions of time make a difference in realizing evaluation results. We conclude our paper by outlining where we see the IYFP project moving, based on our experiences thus far.

\section{RECOGNIZING METHODOLOGICAL DIFFERENCE: KEY IDEAS}

The literature identifies several areas where there may be challenges in bridging Western and Indigenous ontologies and epistemologies in the conduct of evaluations 
in community contexts. Some of these are described as framing research designs in the Indigenous Youth Futures Partnership project.

In order to bridge difference and fully embrace the fundamental principles underlying Indigenous epistemologies, Smith (1999[MM1], p. 4) maintains that for Indigenous nations and communities to survive, research and evaluation must ultimately serve the purpose of remaking those communities "within a wider framework of self-determination, decolonization and social justice." Part of this space-making involves the establishment of local research protocols and the creation of Indigenous methodologies (Kovach, 2009; Wilson, 2001) that adhere broadly to the following:

- building respectful relationships between the topic of research and the researcher;

- $\quad$ ensuring that methodologies are respectful of relationships with participants;

- $\quad$ creating stronger joint relationships with the ideas being shared;

- defining carefully the roles and responsibilities of the researcher;

- $\quad$ ensuring self-awareness as a researcher regarding relationships with participants; and

- determining the reciprocal benefits of the research, including creating the conditions for growth, learning and sharing. (Wilson, 2008, p. 77)

In addition to these considerations that apply especially in Indigenous contexts, universal scientific research principles also hold that researchers have to comply with what is legally appropriate, ethical principles must be respected, data must be gathered according to sound methodological rules (Groh, 2018). The unique challenge of accomplishing this with respect to evaluation in Indigenous contexts is that, as researchers and evaluators, we may interpret perceptions of difference in ways consistent with our own cultures of origin, which may lead to erroneous conclusions because we lack an understanding of Indigenous ways of knowing. As a result, vigilant self-scrutiny regarding the premises of those interpretations must occur, and we must invest time to understand local contexts. Equally important, correlations that may be regarded as obvious in one's own context may not be applicable in the other as a result, especially in Indigenous contexts (Groh, 2018, p. 108).

Some important methodological choices have to be acknowledged when working in Indigenous contexts, each of which will be illustrated in our discussion of the Indigenous Youth Futures Partnership project. First, there are many ways to understand cultural insights, but a common point of reference is recognizing different epistemological traditions with respect to a focus on the specific versus the general. Groh (2018, p. 109) explains that a central objective of cross-cultural research "is the search for culturally specific versus universal phenomena," meaning that the researcher must be able to distinguish between what characteristics can be explained in some cultures versus in all cultures. The advantage is that this allows researchers to detect social and other cultural patterns with the objects of 
study that may be used to examine whether these exist in other cultures. However, this is a Western approach that treats culture as an independent variable, rather than an approach that views relationships as something to be explored (Bortolin, 2011). One resulting weakness in applying Western approaches in this context can be observed in sampling techniques. Sampling subsets of populations according to Western approaches is based on the assumption that some subset would characterize the whole, given an appropriate sample selection and size (Chilisa, 2012; Hofstede, 2001). However, in colonized subsets of populations such as Indigenous communities in Canada (Borrows, 2016[MM2]), any assumptions regarding application to the whole most likely would not hold, even between one nation or community and another (Bowman, 2017).

Second, choices and means of data collection are a fundamental consideration. In Indigenous epistemologies that value relationships, qualitative empirical data is more likely to be valued more highly than quantitative data, which may be at odds with what constitutes sound evidence in post-positivist or other forms of Western-based evaluation. Realistically, quantitative data may not be available or may be considered less reliable. If quantitative data can be collected, then it must be based on full, free, prior and informed consent as it respects UNDRIP (United Nations, 2008, p. 32) and the Tri-Council Policy Statement on Ethics in Research (TCPS-2) (Canada, 2014). Communities should therefore be involved in the design of data collection that matters to them. Even in qualitative studies, the means of data collection must be considered carefully so as not to destabilize traditional cultures, must be as non-invasive as possible, and must respect the tenets of informed consent.

Third, notions of validity may be considered by Western-trained evaluators as important when one considers that "all the psychological mechanisms are at work that have an influence on perception, interpretation, and resulting behaviour" (Groh, 2018, p. 115). For Groh (2018[MM3]), researchers with globalized experience are highly valued by Indigenous communities and leaders, and their mere presence exerts influence. Being vigilant about one's own influence is critical for building respectful relationships, as local populations may subjugate their own influences due to beliefs of their own inferiority and thinking that they cannot compete with globalized researchers on their terms, which may contribute validity problems (Groh, 2018, p. 116). Researchers trained in the Western tradition must be mindful that their actions are not neutral. Careful thought must be given to balancing reactions to one's presence and behaviour in a dynamic and constantly changing series of interactions in a community. Various forms of internal and external validity should be addressed insofar as real-life situations can be regarded as valid (Shadish, Cook, \& Campbell, 2002). As indicated in the introduction to this special issue, there has to be a change in mindset on the part of Western researchers to work with communities, and not to identify these as research objects in the positivist sense (Wehipeihana, 2018).

Fourth, Western notions of reliability reflect a post-positivist idea that repeated investigations yield the same results regardless of context, circumstances, measurements, and other factors. This is particularly important when designing 
and assessing program interventions that hold the promise of supporting local priorities. Although the prevailing literature on Indigenous approaches to evaluation highlight the importance of local context over generalizability (Cram et al., 2016) or even suggest that attempts at generalizability are not a major goal or consideration (Bowman, 2017), Western approaches would suggest that if reliability is ignored, then Groh (2018[MM4], p. 119) maintains that "this could lead to a case of false alarm, so that interventions would take place, which interfere with the Indigenous people concerned and, in effect, destabilize their social system; or the necessity of interventions could be overlooked, so that the chance of intervention would be missed and the suffering of the Indigenous community would continue or even worsen." Governmental evaluation still places great value on the attempt to generalize so that there is some coherence in public policymaking and the design of appropriate programs that serve as many communities as possible. The value of generalizability may be tempered by repeated visits to local contexts in order to mitigate the effects of desires to generalize in ways that might harm communities. Local precision thus becomes a shared learning opportunity.

Fifth, the objectivity of findings is important for supporting whether research findings pertain fully to the issue or object of study. Objectivity is said to be established when the researcher has no influence on results, and it is a necessary condition of any scientific study (Shadish et al., 2002). In Indigenous contexts, objectivity means reducing the cultural influence of the researcher. For example, one would not want local participants to behave any differently whether the researcher is there or not, which would also be an internal validity consideration. Another validity consideration is being clear about the evaluative criteria being applied in the study, so as to reduce comparability errors across researcher interactions. Properly and accurately describing the research methodology is critical to valid research in Indigenous contexts (Battiste, 2007).

\section{UNDERSTANDING DIFFERENCE: THE INDIGENOUS YOUTH FUTURES PARTNERSHIP}

The Indigenous Youth Partnership project (IYFP) was established in 2016 and funded by the Social Sciences and Research Council of Canada (SSHRC) for seven years. The IYFP project team is composed of several university researchers, First Nation communities and organizations, and nonprofit groups. It began working with self-identified communities in the Sioux Lookout zone in northwestern Ontario: Bearskin Lake First Nation, Kasabonika Lake First Nation, Fort Severn First Nation, and Mishkeegogamang First Nation. The project is being led by Carleton University and a principal regional partner-the Sioux Lookout First Nations Health Authority (SLFNHA).

The project's principal aim is to work with communities and First Nation organizations to understand the conditions necessary to create resilient communities that enable the next generation to address the effects of intergenerational and other traumas, to lead a good life, and to become the next generations of leaders, 
in the broadest sense. The project understands "resilience" to mean the "ability of systems and people to effectively respond and adapt to changing circumstances and to develop skills, capacities, behaviours, and actions to deal with adversity." As a process, resilience means the ability to withstand significant social and other shocks (IFRC, 2014). From an evaluative standpoint, such shocks can be mitigated through the strength of programmatic interventions, partnerships, effective communication and education strategies, community-based and community-led projects, and longer-term programs that build on past interventions. Each of these elements can be evaluated with the singular goal of creating stronger communities along theories of change that are community designed and guided. Ultimately, the point of resilient communities and youth is to reach a state of bimaadiziwin (Toulouse, 2001) an Ojibwe word that translates roughly into a lived notion of the good life in the most holistic sense. The concept embodies the ideas of both becoming healthy in spirit and body, and living a healthy life, having achieved balance through well-being and nurturing healthy relationships.

The research component of IYFP works to understand two equal and parallel inquiries: a set of framing research questions that focus on knowledge about bimaadiziwin, and a set of community-focused questions that deal with what communities do to create bimaadiziwin, why they make the choices they do, and how they evaluate progress. Figure 1 shows our research questions and the relationship among them.

At the same time, the project is very engaged with communities on a practical level. IYFP was founded on the idea that a multidisciplinary team of researchers (including anthropologists, geographers, public policy and administration specialists, and psychologists, just to name a few) teaming up with a variety of health and social service organizations in the Sioux Lookout region could offer expertise and resources that communities could access to assist them as they proceed along their path to bimaadiziwin. IYFP researchers have, for example, been working to support communities as they develop the concept for a youth centre, while others are creating strategies to engage youth in developing the confidence and social skills to pursue their aspirations, and others are making salient the linkages among youth to be peer supports.

At yet another level, the Indigenous Youth Futures Partnership has a policy component. The objective is to build on community initiatives and experiences to contribute to improving institutional and program arrangements and achieving better public policy over the longer term. This will be achieved by holding a series of policy forums with key partners in the project, and with the federal and provincial governments to move conversations about community-based governance and programming forward in policy dialogues.

The project is governed by a Steering Committee of policy and community experts (both Indigenous and non-Indigenous), whose role is not necessarily to direct the project but rather to flag any epistemological and methodological opportunities that could be pursued to promote the project's goals, or any concerns it believes could cause harm to the project's participants and partners. This 


\section{The Big Questions}

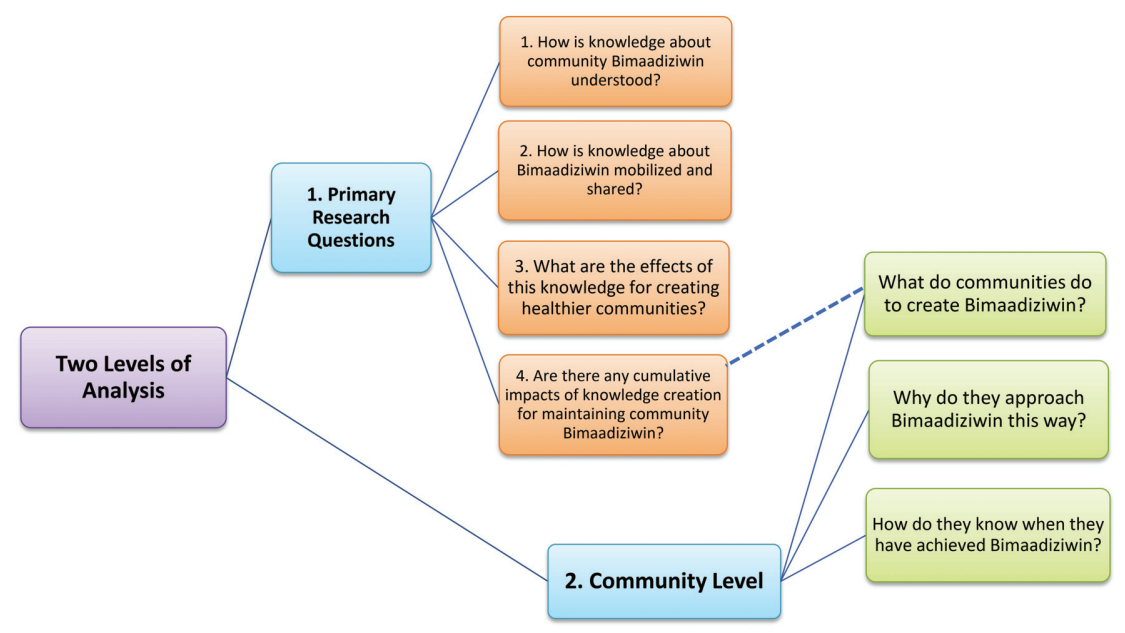

Incremental Research Approach

Figure 1. The big questions

committee has been meeting twice annually. The routine work is guided by a Program Committee that pays attention to matters of research planning, research streams or activities, data gathering and analysis, reporting, and evaluation. It meets three times annually. There are sub-committees that meet on an as-needed basis, including an evaluation committee that has contributed to ongoing research planning, research metrics, and providing advice on appropriate evaluation approaches. Most notably, it created meta-theories of change that provide guidance on the various streams of research. Each major theory of change is further elaborated by more detailed sub-theories of change, as shown in Figure 2. The meta-theory of change is described generally as follows:

- If the team can create understanding of ways of knowing and understanding (as appropriate in the communities we are working with), then an appropriate relationship can be established between the team and communities to work with youth.

- If such relationships can be established, then the capabilities of communities can be better understood from a youth perspective at the social, economic, and collective levels of analysis.

- If these capabilities can be captured using various tools such as asset mapping (Haines, 2015), then youth can be empowered through good 


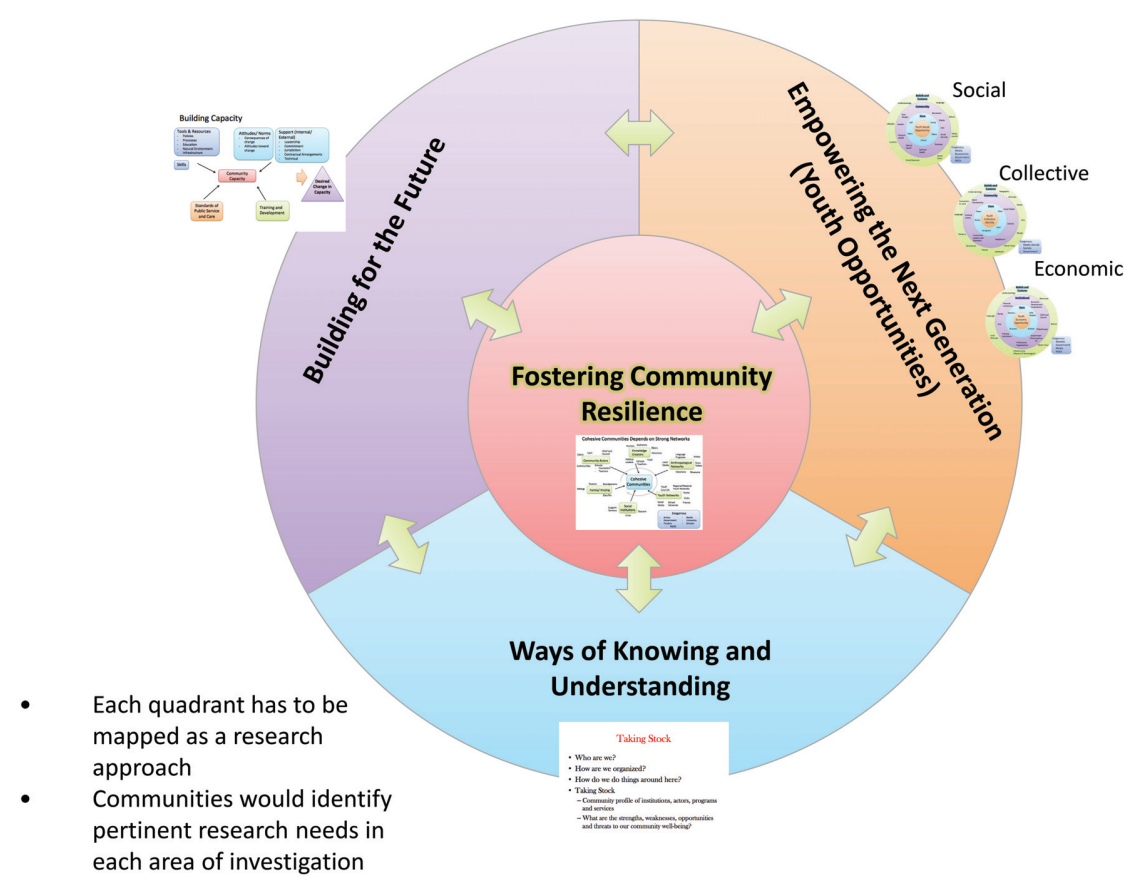

Figure 2. Meta-theory of change for IYFP

information to create opportunities for greater engagement with programs, services, and community leaders to build for their futures.

- If capabilities can be strengthened for the future, youth are better positioned to assume effective community roles and contribute to the wellbeing of youth in their communities.

- If such capabilities and participation can be generated, then the conditions for resilience can also be strengthened.

The challenges of working through such theories of change from the standpoint of the research project are significant, and the research challenges raised earlier are pertinent; this is the subject of the next section, based on our evaluation experiences so far. As resilience is our major focus, the subjects of evaluation (evaluands) are several. At this point in our project, the most significant of these is youth engagement and intersections with youth programs at the community level.

To understand engagement, two communities (Fort Severn and Kasabonika Lake) have established youth apprenticeship programs. These aim to recruit and work with youth in their late teens or early 20 s who have, at a minimum, graduated from high school. Their role is to establish the means to gather information and work with youth in their communities. Their main role in the early stages of the IYFP is to help guide community mapping of the assets within communities 
(e.g., programs, places, people) that contribute to community life. This element of the project provides some epistemological, methodological, and ethical challenges in identifying what youth consider to be their main points of programming and contact. Separating the evaluation function from the identification function has been important at this stage.

Each of the two communities has approached the governance of youth apprentices in different ways. In Fort Severn, the Chief has taken direct interest in the work of two youth apprentices and has established informal means to guide their work through a mentor who was associated with the project and had familial ties to the community. The youth regularly consult with and are guided by the mentor and a faculty member from the project, who regularly visit the community and take part in their efforts.

In Kasabonika Lake, four youth have been engaged: two through IYFP and two funded by the Choose Life program (a federally funded but community-based program designed to provide youth at risk with activities). Two faculty members are responsible for guiding their research activities. In addition, the work of the apprentices is assisted by a community-identified "mentoring committee" comprising six leaders from various social program areas and the councillor responsible for youth programs. The role of the mentoring committee is twofold: to provide ongoing support to the youth when faculty members are not in the community, and to ensure that the youth activities have the support and commitment of the wider community.

In both communities, the youth apprentices use various tools to access other youth, including social media platforms such as Facebook, attending various community events and festivals, organizing activities and events that attract youth from different age groups to participate in data gathering, and working regularly with the school through organized events or organizing their own events. Information about what programs youth regularly know about and access is obtained from various age groups. The data from these different cohorts are treated separately for the time being, until they can be analyzed. The apprentices participate in regular discussion and training sessions with faculty in areas such as research ethics (e.g., consent, confidentiality, and data storage), basic qualitative research methods, PhotoVoice (i.e., as a data-gathering approach), and approaches to communications (between the team and fellow youth, as well as community leaders). In Fort Severn, youth apprentices have been engaged in an extensive training program on media.

The apprenticeship program, and larger efforts by the team to work with community leaders and representatives on youth programs, is the focus of the next section. It attempts to highlight the challenges already identified, as well as the evaluative approaches and tools that have been or could be used potentially to work through them. It is important to note that the project's evaluative activities are still in their infancy in these communities, which means that a great deal of experimentation is occurring around the choice of evaluative tools and approaches, and their strengths and limitations in Indigenous contexts. 


\section{NAVIGATING DIFFERENCE: APPLYING EVALUATION APPROACHES}

\section{Addressing the challenges of cross-cultural research and objectivity}

Several challenges have been observed and experienced by the IYFP team in their efforts to establish their research programs within communities. These challenges relate to evaluating programs and services, governance arrangements, tools and instruments, engagement, protocols, or relationships of various sorts depending on the community's needs.

One of the main challenges of the IYFP partnership, which comprises both Indigenous and non-Indigenous researchers, is gaining knowledge and understanding of the communities themselves. Most of the principal researchers have several years of experience with Indigenous communities and organizations, but it still takes time to create effective working trust relationships.

A major challenge of cross-cultural research is addressing the notion that all research has to be generalizable in some way in order for it to be considered valid epistemologically and methodologically (Chilisa, 2012). However, this thinking is limited and limiting in the sense that research and evaluation in Indigenous contexts both within and between communities are about understanding coherence and balance between body, mind, and spirit (Wilbur, 2000), or what some Indigenous scholars have called the "interior" and "exterior" (or "outside") to life and its experiences (Battiste \& Henderson, 2000; DeChardin, 1959), while others refer to understanding, perception, and intelligence (Cram, Pipi, \& Paipa, 2018), and still others to the "holographic universe" (Meyer, 2016). The outside is the physical, empirical, and objective side, whereas the interior is the mental, hermeneutic, and subjective side.

The concerns of Meyer (2016) that one has to understand what is distinct before one can compare are well founded, but there is a predisposition on the part of Western positivist science to create sampling plans in advance of fieldwork that account for ways to compare. In the IYFP project, such plans are not possible until the "distinct" is determined by understanding culture, context, and conditions. That said, some planning is possible to adjust to Indigenous epistemologies, including building theories of change in a dynamic way over several community visits. This is contrary to practices outlined in the literature that often call for these to be created in advance, with assumptions pre-identified through pre-consultation efforts and tested in the field (Funnell \& Rogers, 2011).

In order to bridge these approaches, the IYFP has created research agreements with communities, including protocols for collaboration and data collection. At a minimum, such efforts have ensured that expectations are calibrated between the researchers and community leaders and that there are ways to address potential problems when they arise, as they invariably do. In this respect, research and evaluation are regarded by the IYFP team as dynamic, flexible, and subject to regular amendment. This is a reality of the work that IYFP does. The approach raises the possibility that theories of change are themselves dynamic 
and are living constructs to be explored and amended as new insights arise. This makes testing more challenging for various reasons, not least of which is the multiplicity of evaluands. These must be thought of in relational terms, meaning that individuals and groups will each have their own particular relationship (constructivist) but that there is great weight also assigned to community value judgements, which must also be accounted for in the evidence chains (Mertens \& Wilson, 2012[MM5]). Balancing both collective and individual perspectives from a physical, intellectual, and spiritual point of view creates highly sophisticated conversations, often through narrative storytelling that is not always easily translated into Western understandings.

Also at the community level of analysis, Western notions of relying on models and constructs to understand "reality" is practically ineffective, as these force or privilege compartmentalized thinking, especially in evaluation where one must always stay focused on the evaluand(s) by scoping the targets or objectives and then measuring or validating whether these are being met programmatically. In our own work, such ideas do not always hold as community engagement is not a program to be researched, but multiple relationships to understand and nurture. As indicated in the introduction to this edition, how engagement is conceptualized is critical to determining the strengths and limitations of the relationships involved (youth.gov, 2019). By extension, youth engagement with leaders, elders, or other youth is not understood simply in terms of the results of that engagement, but rather in terms of the value (i.e., constructivist underpinnings) associated with the purpose and means to generate other relationships that build toward a collectively held and valued idea or project (Cram et al., 2018). In practice, according to "Indigenist" thinkers, this places greater value on the naturalistic versus humanist ontological frame (Smith, 1999). That is, it places the Indigenous voice at the centre; values gender-based perspectives and the special role that women play in community; relies on oral knowledge, memory, and tradition; values personal gifts that benefit all, as well as narrative storytelling in the first person, where personal truths are held in higher esteem than universal truth. This is in fact the Anishnaabe value system to knowledge and sharing that guides the IYFP project (Gehl, 2017). This is such a contrast to positivist and humanistic Western approaches to understanding that it has led to "data collection" meaning having deep conversations with many people before one can articulate a finding in the traditional sense.

As an extension of this last point, understanding the subjects of evaluation between community contexts is also difficult and poses many of the usual challenges of comparisons among samples (e.g., competing external validity problems). All of the communities in the IYFP partnership demonstrate different approaches to governance, decision making, and involving youth. Community context is critical for understanding the differences between knowledge, knowing, and understanding — or what Meyer (2016) [MM6] calls the "third laser" that illuminates an object or idea. For him and others, including Bowman (2017), one must first get to know what is distinct about individuals and communities in 
order to draw comparisons, including incorporating spirituality in evaluations (Luo, Liu, \& Liu, 2018). That said, this requires a research approach that values the flexibility and dynamism that this perspective implies. It also requires evaluative approaches that give agency to communities to hold the levers of control from design to implementation, such as participatory evaluation (Cousins \& Whitmore, 1998) or culturally responsive evaluation (Guba \& Lincoln, 2000[MM7]; Hood, Hopson, \& Kirkhart, 2015), the latter of which ensures that cultural context is acknowledged in the selection and treatment of the evaluand. Drawing comparisons among the subjects of evaluation between these community contexts poses research challenges for generalizability. One is compelled to look for key themes at the meta-level in terms of the process of research and evaluation, yielding perhaps some findings that point toward higher-order evaluands such as resilience. However, many of these higher-order findings can themselves contribute in some way to end states such as resilience. The IYFP is not yet at the point where it is able to design applicable analytic models for engaging youth and communities, which remains a preoccupation. This is not to say that this is of principal concern presently to the team, but for funding agencies that look for generalizability, there is some pressure to come to such findings in whatever form these may take, based on the evidentiary trails that are created.

In addition to these challenges cited by Groh (2018), the IYFP team has learned that it takes a certain amount of humility and patience to approach Indigenous organizations and communities. Although this may appear an obvious point, and indeed is well described in the literature (Cram et al., 2016), it is much more difficult to practise in reality. A key consideration is the pace at which relationships are developed. It can be painstakingly slow, especially as the time needed to fly into remote communities is a major investment physically and mentally, not to mention financially. Patience is a virtue that is tested continuously, as trips to communities cannot often be planned in advance, given limited communications or even the ability of the busy local leaders to even respond. Furthermore, plans are often subject to change based on the reality of circumstances at the time-previously agreed-to aims of research trips may not be a priority in the moment they actually occur. Practising humility and patience is a real challenge, especially when it is not always apparent whether progress in the Western sense is being made. Measurable progress in terms of creating a spark of interest in one's research or evaluation, intentions, or plans is sometimes difficult to determine until some time in the future when, for example, someone remembers a comment, action, or conversation that garnered support, which then turned into a commitment to follow up.

In addition, most on the research team have learned Western approaches to research and evaluation that have limited efficacy in these communities (Hornung, 2016). It is often the case that Western approaches are regarded as superior in some ways to local ones, which can manifest in presumed acceptance, especially when limited feedback is provided (e.g., in Anishnaabe communities, feedback may not be given directly out of respect for the visitor). Hornung's (2016) approach of consulting before acting, negotiating use of tools or approaches, and 
creating understanding for their benefits, while respecting the land, peoples, and culture (e.g., valuing local knowledge systems) that leads to agreed outcomes, has been key in the project's approach in all four communities, and with Indigenous organizations and services. In our experience so far, the perspective of community leaders and regional partners has been noteworthy. There has been acknowledgement that Western tools may strengthen reliance on local resources and cultural traditions and initiatives. Acknowledging that Western-learned approaches are but one way to understand how communities work and address local problems/challenges has been instrumental. This acknowledgement also assumes fundamentally that it is not always appropriate or desirable for non-Indigenous researchers and evaluators to ultimately guide or even participate in the research and evaluation effort. Humility extends as far as recognizing a strength-based approach to working with communities, including perceived areas where control over research projects may get in the way of maintaining and respecting cultural integrity (Bowman, 2017). Co-creation and co-production of research and evaluation products means working with relationship-building talents and skills that can be used to advance important and sensitive conversations with local community members.

\section{Addressing ethical choices in research and design constraints}

Much has been written on the ethical considerations regarding the planning and conduct of evaluation studies in Indigenous contexts (Battiste \& Henderson, 2000; Cram \& Mertens, 2015), and much more can be gleaned from the literature on ethical evaluation practice that attempts to bridge Western and Indigenous ways of knowing. However, we focus here on the contextual issues that influence ethical research in IYFP communities.

Balancing and reconciling Indigenous and Western "scientific" perspectives is omnipresent for the IYFP project team. This extends to the governance of the project, which is guided by a Steering Committee consisting of First Nations, Métis, and settler members, all of whom have education based on the Western positivist paradigm and some of whom are steeped in Ojibwe, Cree, and Métis ontologies and epistemologies. The project requires self-checking and self-correcting to avoid both being overcome by linear thinking (Bowman, 2017) or time-bound plans (that rarely turn out) and relying completely on conceptions of evidence that are rooted in hard measures of performance for the purposes of maintaining accountability under the research grant. With bimaadiziwin as the anchoring goal, the team has had to learn to take a holistic perspective, think about a long timeline (Seven Generations), and recognize that "evidence" may be a deeper concept. In this respect, the idea of "two-eyed seeing," or Etuaptmumk in Mi'kmaw, as coined by Elder Albert Marshall (2005), plays a key role in framing research and evaluation ideas. The notion is that we must learn to see out of one eye with the strengths of Indigenous knowledge and ways of knowing, and out of the other eye with the strengths of Western knowledge and ways of knowing, acquiring the ability to see and use both eyes simultaneously. 
Achieving this two-eyed balance is made difficult by the overwhelming influence of the Indian Act and program-funding regimes that privilege governmental (First Nations Band-based) and invariably Western approaches (Smith, 1999). With some exceptions, the federal and provincial programs that offer the prospect of new funds to support community needs have rigid, template-driven application processes that are based on a single program purpose. Furthermore, reporting and accountability are aimed upward to the funder with little, if any, thought to community accountability. The result within First Nations communities is the creation of targeted-funding silos, supported by micro-bureaucracies that create barriers to cooperation among program officials (Borrows, 2016; Shepherd, 2018). Such arrangements often complicate choices with respect to the identification of research and evaluation questions, as managing up for program reporting and evaluation purposes can tend to preoccupy community leaders, eroding relevance for youth.

References have been made to important time elements associated with the Indigenous Youth Futures Partnership. It is a seven-year project (which had a gestation period of over two years). As is normally required in a research funding application, milestones were identified with associated timelines. Evaluating the project's progress has proved to be notional at best. In reality, adaptation and elongation have characterized the project. There are good reasons for this, including the fact that communities have to move at their own pace in becoming familiar with the project and in thinking through what they want to do and what would constitute positive momentum in creating better futures for youth. Given the day-to-day demands on community members and First Nations leadership, this does not happen quickly, which can complicate funder ideas about accountability for the use of grant funds. As such, there is always a fine line between reporting progress toward results that are in constant flux with the project's long-term perspective. A decision had to be made in this regard not to intervene in the crises that too often arise in communities. The approach when bad things happen in a community is to respectfully keep distance until it is appropriate to re-engage. None of this is predictable and can cause some ethical challenges, as there are sometimes requests for help to intervene.

The foundation for work in these northern communities is the commitment of First Nations leaders in the region to their communities and the persistence of youth in believing that their First Nations are their home and that bimaadiziwin is possible. The youth apprentices believe strongly that they can make a difference in their communities but communicate that they have to be the ones to determine how best to work with their people given the context described. The challenge in communities is diverting energy, talent, and resources to a project that is aimed at the long term, rather than focusing on the immediate. This invariably involves choices to evaluate process toward bimaadiziwin, rather than immediate or shortterm results that address crisis points. Ethical choices have been made in the project to remain focused on long-term aims and remaining steadfast on testing theories of change, but it means also demonstrating reciprocity to community leaders who often demand short term help. 


\section{Addressing the validity and reliability of the evidence}

As with many of the issues raised to this point, there are technical considerations related to the validity and reliability of evidence and evidence claims, and as with any major research project where evaluation is concerned, precautions are taken to preserve the integrity of evidence (Groh, 2018). However, in Indigenous contexts it is often the relational or epistemological aspects of what constitutes evidence and the appropriateness of that evidence in Western thought that pose challenges, particularly from an ethical perspective.

First, validity considerations, such as what constitutes evidence, were carefully considered by the IYFP team, at both the proposal and data-collection stages. To begin, community leaders were asked individually in the early stages of the project what they felt was important to understand about their communities. These queries were then extended to larger group discussions with public officials and community members, including youth, implying that reliability of what the team heard could also be ensured through repeated testing. What we heard led to initial attempts at theories of change and the desire to create or generate resilience in programs, systems, and procedures, especially as these relate to youth needs. These helped to frame initial attempts at developing research questions. These conversations were invariably dynamic, involving the community over several months of repeated visits, documenting both individual and group conversations and replaying those conversations on subsequent visits to validate them with others who may not have participated previously. The conversations were constructivist in the sense that inductive reasoning was used to frame them through broad and open-ended questions regarding community needs, especially those of youth. It meant that researchers' hypothesis statements were not introduced in conversations, nor was there "planting" of ideas that the team, as outside observers, felt were important. The processes employed in the IYFP are often regarded as contrary to Western notions of coming to hypothesis statements a priori in research proposals and then testing them. Ultimately, this meant that many hypothetical statements in the proposal were abandoned or amended significantly to account for ongoing community conversations and visits to arrive at broad notions of resilience.

Second, the role of the research team in communities was a fundamental consideration in the research design. As Bowman (2017) suggests, there is a strong need for Western-trained researchers to engage communities in designing research and evaluation questions, but imposing research approaches in ways that could supplant local preferences is to be avoided. This includes current trends toward co-production or co-creation of research and evaluation products whereby the central idea is that the academy in particular must collaborate more with various communities to improve the relevance and usefulness of its work.

Ersoy (2017) argues that in an Indigenous context, co-production implies that there is a level playing field between Western and Indigenous approaches. From a practical standpoint, the IYFP team has learned that this is not the case. For example, in many conversations with individuals and groups, there is a 
tendency on the part of community members to defer to academics, until there is sufficient trust developed to openly question. There is often the temptation to proceed with a Western approach in the absence of feedback, but this is far from valid. Likewise, there may not be a level playing field in terms of "scientific" understanding. The temptation is to proceed with the evaluation or research endeavour using the Western approach, despite what may appear to be co-production. Bowman (2017) suggests that the assumptions of co-production are erroneous and that Western researchers/evaluators must reduce their control and leave space for communities to determine, first, what space they would like to co-produce within and, second, to decide how they would like to take advantage of the space occupied by Western-based researchers. At a practical level, this means that the IYFP has had to continuously validate both its approaches and processes for evidence gathering in the community, aside from ensuring that these meet the standards of TCPS-2. Working with the apprentices in particular has meant striking a balance. Guidance is provided to them on ways to gather and assemble evidence along the theories of change. However, they have discretion about what to research and how to proceed. This may pose some challenges for ensuring the reliability of evidence in Western terms, but it is necessary in terms of the aims and ethical foundations of the project. In a very positive sense, providing the apprentices with some tools to carry out their work is necessary. However, they are empowered and encouraged to use the tools in ways they believe will be most effective because they know their community best. In this sense, they become the "experts" on evaluation in their community.

Third, bridging ways of ensuring reliability of evidence has been an ongoing challenge, both from the standpoint of internal reliability at the community level and between communities and organizations in the partnership. Although there is recognition in the project's overall design that communities drive the design and implementation of the research and evaluation effort, it is not yet resolved how reliability of evidence will be safeguarded when it is aggregated. The means for generating understanding and insights have been achieved mainly through "appreciative inquiry" approaches (Coghlan, Preskill, \& Catsambas, 2003) that focus on the strengths rather than the weaknesses in policies, programs, communities, or organizations. The IYFP team subscribes to the importance of beginning their thinking with what is working well in communities and then attempts to focus conversations on a desired future where the best of what is working can continue to occur more frequently. Communities in the Sioux Lookout zone have long experienced the consequences of trauma, whether it be in the form of removal of children, imposition of curricula, restrictions imposed by government programs and governance, or researchers who take without permission. Or, most importantly, there have been interactions with governmental officials or other agencies who take an expedient approach to "getting the job done" and disregard the value of local approaches and preferences. In this regard, appreciative inquiry forms the basis of the work with the youth apprentices who are encouraged to begin from a premise of strong community and that their judgement matters, and who 
determine from other youth what is needed to bring about even stronger programs and services for them. To date, this approach has worked reasonably well, as it assumes humility to interact with community members without judgement. This is a change in mindset for many of these communities.

In terms of ensuring reliability of evidence between communities, the IYFP has expended considerable effort in ensuring the validity and reliability of local evidence using standard case-study approaches. At a minimum, comparisons will be possible with respect to the conditions that have to be in place for engagement and ultimately resilience to occur. Such an approach assumes that the particular research questions and projects are less important, an assumption that will continue to be tested over time. At the moment, the relationship with communities is the pre-eminent concern, since having reliable evidence when there is the everpresent incentive not to engage or trust the research team is crucial.

\section{CONCLUSIONS: CHARTING THE WAY FORWARD}

The aim of this article was twofold: to describe and acknowledge the challenges of bridging different ontologies and epistemologies in the design and conduct of evaluation in Indigenous contexts, and to explore how many of these challenges have played themselves out in the research and evaluation design and conduct of the Indigenous Youth Futures Partnership. In particular, we are interested in the practical conflicts and overlaps between Indigenous and Western epistemologies in carrying out research and evaluation that is meaningful to advance our collective understandings of the circumstances that communities face daily. In this respect, the article has attempted to discuss practical areas where challenges have been experienced in the evaluative elements of the IYFP project, understanding that Western and Indigenous approaches converge in several respects but diverge in others.

As researchers and evaluators who have been in this space for some time, we have come to appreciate that self-questioning is always integral to research and evaluation design efforts. Likewise, we have also come to know that while many of the challenges discussed throughout the article are real and important, there are no tangible rules or steps that provide clear direction on how to conduct research and evaluation projects, given the differences in perspectives. Rather, these are merely dimensions of awareness that ought to frame one's own awareness of epistemological bias and the external systems or cultural biases that privilege non-Indigenous preferences for research and evaluation questions and how to approach them. For many on the IYFP team, the intersection of Western and Indigenous epistemologies is not dichotomous, and each member has evolved in their own understandings and in how to apply these to the research and evaluation effort. For example, using strength-based approaches to data collection such as "asset mapping," which takes account of how the community values the roles of people, places, and programs/services/events, is critical as a first step. Such techniques provide the evaluators with starting points of understanding that allows 
participants to approach conversations with respect and sensitivity from multiple perspectives, based in an Anishnaabe understanding of relationships. Indigenous approaches to knowing, therefore, would recognize the value of understanding how communities understand the value of a program, for example. However, the manner in which such understanding is conceptualized and expressed would be much deeper, with many more layers of relationship of community being acknowledged. Given such convergences and divergences, however, and despite decades of experience working in and with Indigenous communities, there are always layers of personal awareness and practice that have to be revisited frequently in order to work effectively. The challenges posed here are mere starting points for any researcher and evaluator, including the team members on this project, to acknowledge.

What separates research and evaluation in Indigenous contexts from other contexts (Mertens, 2018) is that epistemology and local context are different and not easily compared. Understanding relationships to people and places is fundamentally different from regarding the subjects of evaluation as objects to be examined. That said, this is only the starting point for appreciating work in these contexts, and evaluation theory has yet to fully understand this crucial point. Even less available in the literature are approaches that can be described as effective or even appropriate. Repeatedly, meetings of the Canadian Evaluation Society (CES) have made this point clear, as more evaluators are entering this unique space. In particular, numerous presentations at the CES annual conference indicate that fundamental to working in this space is not always technical experience but rather understanding, a willingness to exercise humility, respect, and transparency, and relinquishing control over the evaluation project (Bowman, 2017; Cram et al., 2016; Kovach, 2009). Realist evaluation (Pawson, 2013) is one epistemological approach that may be useful, as it focuses on what works, under what conditions, and why. The importance placed on context and conditions and the testing of assumptions is critical to evaluation in Indigenous contexts. Realist evaluation in combination with appreciative inquiry could be one practical way of bridging Western and Indigenous approaches. Understanding "what works," for example, goes beyond mere qualitative sampling and interviews. It involves recognizing that the value proposition of a program or service, or what it means for something to be working, for instance, requires extending conversations to a wide number of people in the community who may have different conceptions of that value in the constructivist sense (Mertens \& Wilson, 2012[MM8]). These perspectives would provide indications of how the "community," rather than individuals in the naturalistic sense, understand a healthy and vibrant community.

Groh (2018), Mertens (2018), Wehipeihana (2018) and Bowman (2017), among others, make the point that the use of the word "research" or "researcher" in Indigenous contexts has become tainted. This has resulted from the less than admirable history of working in rather than with communities in ways that further the aims of researchers as opposed to the communities they purport to serve. We suggest that "evaluation" as a word may be thought of in similar ways, 
as governmental evaluation has tended to focus more on matters that are of interest to donors or funding agencies, such as accountability for use of funds, than on the interests of communities, despite the rhetoric to the contrary. In addition, evaluators have been accused of using approaches that presume some authority to evaluate without the need for permission or even being mindful of local authority or knowledge systems. Perhaps a new lexicon is needed that better describes the purpose of evaluation in an era of reconciliation (Shepherd, 2018) in order to move relationships among government, Indigenous communities, and engaged organizations forward by changing the intent and processes of evaluation. Several efforts by the Canadian Evaluation Society, American Evaluation Association (AEA), and the Australian Evaluation Society (AES), among others, are attempting to shift the nature and tone of evaluation in Indigenous contexts through ongoing national and regional conversations and workshops with practitioners. EvalIndigenous is also attempting to educate practitioners about the importance of culturally appropriate and strengths-based approaches. However, perhaps a shared and ethical space (Ermine, 2007) where all have a voice in the definition and framing of evaluation as a field that affects them is warranted. Fundamental to creating ethical space is active listening with Indigenous communities leading the conversation, including how to frame the conditions for co-creation and coproduction.

Finally, we suggest, based on our collective experience thus far, that evaluation in Indigenous contexts must place a priority on multidisciplinary lenses in the design, delivery, and reporting of results. Indigenous epistemologies are holistic, and to work in these spaces means drawing on multiple ways of knowing and understanding. Many eyes, ears, and other senses are needed to fully comprehend experiences and relationships in Indigenous communities, which is why the IYFP draws on many disciplines and many types of expertise in order to capture the complex layers of insights that one invariably encounters. Indigenous contexts are exceedingly complex and imbued with many perspectives. This makes evaluation both challenging and exciting, and well worth the journey.

\section{ACKNOWLEDGEMENT}

The authors acknowledge the support of the Social Sciences and Humanities Research Council of Canada.

\section{REFERENCES}

Battiste, M. (2007). Research ethics for protecting Indigenous knowledge and heritage: Institutional and researcher responsibilities. In N. Denzin \& M. Giardina (Eds.), Ethical futures of qualitative research: Decolonizing the politics of knowledge (pp. 111-127). Walnut Creek, CA: Left Coast Press.

Battiste, M., \& Henderson, Y. (2000). Protecting indigenous knowledge and heritage. Saskatoon, SK: Purich Publishing. 
Bortolin, K. (2011). Serving ourselves: How the discourse on community engagement privileges the university over the community. Michigan Journal of Community Service Learning, 18(1), 49-58. Retrieved from http://hdl.handle.net/2027/ spo.3239521.0018.104

Borrows, J. (2016). Freedom \& Indigenous constitutionalism. Toronto, ON: University of Toronto Press.

Bowman, N. (2017). Asserting tribal sovereignty in evaluation and policy studies. Tribal Leader/Scholar Forum of the National Congress of American Indians-Policy Research Institute. Uncasville, CT. Retrieved from https://www.ncai.org/policy-research-center/ initiatives/tribal-leader-scholar-forum

Canada. (2014). Tri-council policy statement: Ethical conduct for research involving humans. Retrieved from http://www.pre.ethics.gc.ca/eng/policy-politique_tcps2-eptc2_2018. html

Chilisa, B. (2012). Indigenous research methodologies. Thousand Oaks, CA: Sage.

Coghlan, A. T., Preskill, H., \& Catsambas, T. T. (2003). An overview of appreciative inquiry in evaluation. New Directions for Evaluation, 2003(100), 5-22. https://doi.org/ $10.1002 /$ ev.96

Cousins, J. B., \& Whitmore, E. (1998). Framing participatory evaluation. New Directions for Evaluation, 1998(80), 5-23. https://doi.org/10.1002/ev.1114

Cram, F., Chilisa, B., \& Mertens, D. M. (2016). The journey begins. In D. M. Mertens, F. Cram, \& B. Chilisa (Eds.), Indigenous pathways into social research: Voices of a new generation (pp. 11-40). New York, NY: Left Coast Press.

Cram, F., \& Mertens, D. M. (2015). Transformative and indigenous frameworks for multimethod and mixed methods research. In S. Hesse-Biber \& B. Johnson (Eds.), The Oxford handbook of multi-methods and mixed methods research inquiry (pp. 91-110). New York, NY: Oxford University Press.

Cram, F., Pipi, K., \& Paipa, K. (2018). Kaupapa Maori evaluation in Aotearoa New Zealand. New Directions for Evaluation: Indigenous Evaluation, 2018(159), 63-78. https://doi. org/10.1002/ev.20331

DeChardin, T. (1959). The phenomenon of man. New York, NY: Harper Perennial Publishing. Ermine, W. (2007). The ethical space of engagement. Indigenous Law Journal, 6(1), 193-203.

Ersoy, A. (2017). The impact of co-production: From community engagement to social justice. Bristol, England: Policy Press.

Funnell, S. C., \& Rogers, P. J. (2011). Purposeful program theory: Effective use of theories of change and logic models. Thousand Oaks, CA: Jossey-Bass.

Gehl, L. (2017). Claiming Anishnaabe: Decolonizing the human spirit. Regina, SK: University of Regina Press.

Groh, A. (2018). Research methods in indigenous contexts. Cham, Switzerland: Springer.

Guba, E., \& Lincoln, Y. (2000). Paradigmatic controversies, contradictions, and emerging confluences. In N. Denzin \& Y. S. Lincoln (Eds.), Handbook of qualitative research (pp. 163-188). Thousand Oaks, CA: Sage.

Haines, A. (2015). Asset-based community development. In R. Phillips \& R. H. Pittman (Eds.), Anintroduction to community development (2nd ed.). New York, NY: Routledge. 
Hofstede, G. (2001). Comparing values, behaviors, institutions and organizations across nations (2nd ed.). Thousand Oaks, CA: Sage.

Hood, S., Hopson, R. K., \& Kirkhart, K. (2015). Culturally-responsive evaluation: Theory, practice and future implications. In K. Newcomer \& H. Hatry (Eds.), Handbook on practical program evaluation (pp. 281-317). San Francisco, CA: Jossey-Bass.

Hornung, F. (2016). Indigenous research with a cultural context. In D. M. Mertens, F. Cram, \& B. Chilisa (Eds.), Indigenous pathways into social research: Voices of a new generation (pp. 133-152). New York, NY: Routledge.

IFRC. (2014). IFRC framework for community resilience. Geneva, Switzerland: IFRC. Retrieved from https://media.ifrc.org/ifrc/wp-content/uploads/sites/5/2018/03/IFRCFramework-for-Community-Resilience-EN-LR.pdf

Kovach, M. (2009). Indigenous methodologies: Characteristics, conversations, and contexts. Toronto, ON: University of Toronto Press.

Luo, L. P., Liu, Y., \& Liu, Y. (2018). Spirituality matters: The role of religion in development project evaluation in the Tibetan communities in China. In F. Cram, K. A. Tibbetts, \& J. LaFrance (Eds.), New directions in evaluation: Indigenous evaluation (Vol. 159, pp. 97-106). Thousand Oaks, CA: Jossey-Bass.

Marshall, M. (2005). On tribal consciousness: The trees that hold hands. World Indigenous Peoples' Conference on Education, Hamilton, Aotearoa / New Zealand. Retrieved from http://www.integrativescience.ca/uploads/articles/2005November-Marshall-WIPCEOn-Tribal-Consciousness-Integrative-Science.pdf

Mertens, D. M. (2018). Mixed methods design in evaluation. Thousand Oaks, CA: Sage.

Mertens, D. M., \& Wilson, A. T. (2012). Program evaluation theory and practice: A comprehensive guide. New York, NY: Guilford Press.

Meyer, M. A. (2016). The context within: My journey into research. In D. M. Mertens, F. Cram, \& B. Chilisa (Eds.), Indigenous pathways into social research: Voices of a new generation (pp. 249-260). New York, NY: Routledge.

Pawson, R. (2013). The science of evaluation: A realist manifesto. Thousand Oaks, CA: Sage.

Shadish, W. R., Cook, T., \& Campbell, D. (2002). Experimental and quasi-experimental designs for generalized causal inference. Boston, MA: Houghton Mifflin Company.

Shepherd, R. (2018). Indigenous peoples and the reconciliation agenda: Funding, accountability and risk. In C. Dunn (Ed.), The Handbook of Canadian public administration (3rd ed., pp. 246-268). Toronto, ON: Oxford University Press.

Smith, L. T. (1999). Decolonizing methodologies: Research and Indigenous peoples. New York, NY: Palgrave.

Toulouse, P. R. (2001). Bimaadziwin (the good life): Sharing the living teachings of the people of Sagamok Anishnawbek: Implications for education (Doctoral dissertation). University of British Columbia, Vancouver, BC. Retrieved from https://open.library.ubc.ca/ cIRcle/collections/ubctheses/831/items/1.0055503

United Nations. (2008, March). United Nations Declaration on the Rights of Indigenous Peoples. Retrieved from www.un.org/esa/socdev/unpfii/documents/DRIPS_en.pdf

Wehipeihana, N. (2018). Affirming and privileging Indigenous knowledge in evaluation. Canadian Evaluation Society 2018, Calgary, AB. Retrieved from http://nwtevaluation 2018.com/presentations.html 
Wilbur, K. (2000). Sex, ecology, spirituality: The spirit of evolution. Boston, MA: Shambhala Publishing.

Wilson, S. (2001). What is an Indigenous research methodology? Canadian Journal of $\mathrm{Na}$ tive Education, 25(2), 175-179.

Wilson, S. (2008). Research is ceremony: Indigenous research methods. Black Point, NS: Fernwood.

youth.gov. (2019). Assessing youth involvement \& engagement. Retrieved from https:// youth.gov/youth-topics/positive-youth-development/how-do-you-assess-youthinvolvement-and-engagement

\section{AUTHOR INFORMATION}

Robert P. Shepherd is associate professor at the School of Public Policy \& Administration at Carleton University. His research spans public management and governmental reform, Indigenous public management, ethics, and policy and program evaluation. He is interested in how public accountability and oversight systems intersect to improve overall public management and governance systems. In addition, his research extends to understanding how governmental program evaluation functions can improve public policy and decision making.

Katherine A. H. Graham is professor emerita at the School of Public Policy \& Administration at Carleton University. Her research interests concern Indigenous and northern development policy, urban and local governance, and institutional reform in government. Community-based research is an important pillar of her work. She is the founding coordinator of the Carleton University Institute on the Ethics of Research with Indigenous Peoples (CUIERIP). Katherine is currently working on youth and community capacity building in northwestern Ontario. 